\title{
Impact of Social Needs on Participation of Children Aged 4-6 with Disabilities in Early Childhood Education Classes in Starehe Division in Nairobi County, Kenya
}

\author{
Ganira Khavugwi Lilian, Paul Amolo Odundo, Boniface Ngaruiya, Rose Obae
}

School of Education, College of Education and External Studies, University of Nairobi, Nairobi, Kenya

Email address:

kganira@yahoo.com (G. K. Lilian), odundopaul@yahoo.com (P. A. Odundo), bngaruiya@uonbi.ac.ke (B. Ngaruiya), roseobae@gmail.com (R. Obae)

\section{To cite this article:}

Ganira Khavugwi Lilian, Paul Amolo Odundo, Boniface Ngaruiya, Rose Obae. Impact of Social Needs on Participation of Children Aged 4-6 with Disabilities in Early Childhood Education Classes in Starehe Division in Nairobi County, Kenya. International Journal of Elementary Education. Vol. 4, No. 2, 2015, pp. 25-34. doi: 10.11648/j.ijeedu.20150402.12

\begin{abstract}
Social needs are essential components for preventing anxiety, depression and loneliness. Providing social needs of belongingness, self-esteem and self-acceptance and fostering resilience in children living with disabilities is likely to amount to sustained coordinated efforts to support children's psychological, social-emotional and academic development throughout early childhood and adolescent. CWD need opportunities to cultivate their skills, competences, talents, strength and social relationships, yet too often lack of proper intervention reduces their opportunities for participation. The study assessed impact of social needs on participation of Children with Disabilities (CWD) in early childhood classrooms in Starehe division in Nairobi County. Study adopted descriptive research design and targeted 5 head teachers, 35 teachers, 20 children aged 4-6 with disabilities and 20 parents of CWD. Purposive sampling and simple random sampling was used to select respondents for study. Questionnaires, observation guide and structured interview were used to solicit data. Findings revealed that teachers were not conversant with types of social needs promoting participation of CWD in ECE classes. However those teachers who effectively supported CWD social needs yielded encouraging results in inclusive learning environment. The study recommends policy for early identification on the needs for effective participation of CWD in ECE classes.
\end{abstract}

Keywords: Participation, Disability, Social Needs, Early Childhood Education, Inclusive Learning Environment

\section{Introduction}

Addressing social needs of belongingness, self-esteem and self-acceptance and fostering resilience in children with disabilities is likely to amount to sustained coordinated efforts to support children's psychological, social-emotional and academic development throughout early childhood and adolescent. Early years focus is critical for mitigating barriers for sustained learner participation in ECE and beyond. These barriers include social and cultural attitudes, values, myths about disability, low expectations, physical exclusion and lack of personal safety Davis and Watson, (2001). With sustained and meaningful policy and commitment to act decisively on improving social needs of CWD, improved health and well-being and social inclusion of CWD, stimulates success realized in learner participation at ECE tier.By implementing tangible steps towards appropriate provision of social needs to CWD the likelihood of participation is increased and learner achievement enhanced.

Consequently, without immediate attention to social needs then CWD are likely to continue to have unequal access to participation in ECE and in society. Drawn from this conclusion Carter and Curtis, (2003) points out that the school may be the only stable, secure and predictable element in the lives of CWD. Thus CWD whose social needs are met are likely to adjust better to school situation and transitions as well exhibit high levels of participation. After successively providing social needs it is expected that the behavior of CWD will change and be motivated to acquire skills of problem solving, creativity, decision making, responsibility, tolerance, achievement, confidence, self awareness and contentment which are ingredients for high learner participation and achievement.

Providing for social, physical, emotional and developmental needs of children with disability should be the 
main focus of early childhood education (ECE). However there continues to be a gap between policy decision and on the ground implementation of such needs. Furthermore Richard and Mary (2002) notes that individuals with disabilities need opportunities to cultivate their skills, competences, talents, strength and social relationships necessary for active participation in school and society. However, lack of proper intervention measures of social needs reduces CWD's opportunities for participation in schools and in development of enriching experiences which in turn reduces levels of participation and learning achievement.

In Kenya for instance, persons with disabilities have been consistently viewed as liabilities other than assets Osundwa, (2007. This perception may have been influenced by the way persons with disability have been prepared for life right from pre-school to adulthood. This misconception can only be changed through observance of obligation of the United Nations Convention on the Rights of persons with disabilities that urges nations to take all appropriate measures to eliminate discrimination on the basis of disability, and also adhere to the united conventions on the rights of persons with disabilities.

Studies by Oriedo, (2003) shows that there is a continuing disparity on educational services in Kenya for CWD. As a result, educational services and interventions for CWD are not being addressed adequately. The negative perspective CWD face is a major mitigating factor in provision of efficient intervention measures. Furthermore the government's policy on the education of CWD is implicit and contradicting as it fails to provide effective intervention measures for social needs of CWD. According to UNESCO, (2005) a child's participation in the learning process is influenced by society's knowledge and attitudes, and knowledge to adapt and accommodate various needs of all types of disabilities.

World Bank (2007)notes that recently the focus has shifted from the traditional "medical model" to "social model" that promotes the strength of CWD, focusing not only on the disability, but on ability emphasizing that ability can influence equal level of participation. In support of this view UNICEF,( 2003) argues that increasing support for CWD and shifting the emphasis towards ability requires changing attitudes and strengthening social needs at every level of the school system. In Australia, the creation of the social model of disability has been successful, Rauch (2011). Under this model, barriers to participation for persons with disabilities are overcome through strong legislation, policy and practice across Australian jurisdiction.

Studies by Jones and Murphy (2008) indicate that unfinished explorations, coupled with unclear policies on interventions have rendered CWD slots in society. Furthermore ECE centers are still guided by policies and stereotypes that tend to normalize CWD without considering their social needs, uniqueness and diversities. When CWD fail to attain their potential and when left unsupported, may lead to later social exclusion and adjustment difficulties,
Macy and Bricker (2007). To mitigate such antisocial maladjustments there is dire need to strengthen the provision of social needs that will enable CWD to participate in an inclusive ECE environment. Although much research is needed to demonstrate intervention measures for the participation of CWD, provision of social needs is likely to influence participation of CWD in an inclusive ECE environment and in the larger society.

For CWD school is a centrally important space where a sense of belonging is formed, sustained and supported through formal and informal activities and interactions. Analysis by Kenrich, (2006) revealed that the child, for full harmonious development of his personality, needs a sense of belonging, love and understanding from the immediate environment. This includes caring parents, peers, teachers and an inclusive ECE environment. More still the most powerful human motive is to form and maintain social bonds. Conversely ,Aldao et al., (2010) argues that if an individual's sense of social contentedness is threatened, then his ability to self-regulate suffers Therefore lack of constant positive relationships has been linked to a range of consequences. The CWD who lack social relationships are prone to behavioral problems such as depression, criminality and loneliness. These consequences are likely to impede participation in the learning process. However, CWD who feel part of the classroom community will be better to focus on building healthy relationships of belongingness. These needs are key requisite to the participation of $\mathrm{CWD}$ in an inclusive $\mathrm{ECE}$ environment.

When belonging and connection are threatened CWD experience limited friendship, loneliness and the places they can go within the school are controlled. This tends to impact negatively on effective participation. Baumeister et al., (2009) opined that humans have an inherent desire to belong and to be an important part of something greater than themselves. In the absence of sense of belonging, the individual becomes susceptible to loneliness, social anxiety and depression. Furthermore, Psychological imbalances such as depression, loneliness and anxiety can hinder CWD from obtaining higher levels of participation. In order to avoid this psychological imbalance CWD need to feel accepted and supported by others. If they develop strong connections with friends, family and teachers they will be able to cope with stressing situations. If this is realized then CWD are likely to develop a desire to actively participate in a sustained ECE environment.

To realize optimum learner participation, learners need to be involved in daily routines such as classroom jobs, morning meetings and keeping a predictable schedule that will help them to be more confident to compete as members of an inclusive learning environment. Teachers also need to build a sense of belongingness by developing learners' skills to work with others, play cooperatively, have a sense of empathy and to be part of a team. If this is done then CWD are likely to develop creativity, problem solving skills, decision making skills and self-regulating ideas. Thus a sense of belongingness is significant to the success and 
participation in the learning process for CWD.Analysis by Baumeister et al., (2009) shows that a positive sense of belongingness to a social peer group enhances learner participation. Group membership is associated with more enjoyment at school, while those who do not belong to social group tend to be less engaged in school activities. In support of this view, Dewall, et al., (2011) points out a link between more positive sense of belonging, better academic motivation, better social-emotional functioning and higher attainment of grades. To this end, teachers need to emphasize on activities that provide belongingness if learner participation has to be realized. Such activities include active learning in groups, peer relationships, participatory engagements and positive school environment.

Studies have shown that learners who feel more accepted, included and involved in extra curricula activities, in interpersonal relationships, are more likely to be engaged in classroom learning McMahon, et al., (2008). However without a conducive environment and teaching approaches that encourages and support belongingness then learner participation is less likely to be realized. To this end, teachers need to create cohesive environment where CWD feel important, and give positive encouragement to CWD. When children belong to a social group and when they are accepted and welcomed they are likely to develop positive emotions such as happiness, elation, calmness and satisfaction. For this to be achieved, teachers need to provide a stage for developing skills such as respect for one another, sharing power and valuing diversity. However when CWD are rejected or excluded they feel strong negative emotions of anxiety, loneliness and desolation. Based on this realization, teachers in ECE centers need to pay attention to individual needs of CWD. This can be done through allowing CWD to participate in decision-making within the class, such as helping to develop class rules or behaviors or having some limited choices in terms of academic skills. By so doing, teachers sharpen CWDs' motivated behavior suggesting high participation in the learning process.

Even though there have been few studies for introducing self-esteem programmes in ECE classrooms, high selfesteem has beneficial psychological and physiological aspects. In a similar manner low self-esteem has many detrimental, psychological and health behaviors, Galambos et al., (2006). Moreover for CWD to effectively participate they need high self-esteem. This demands love and encouragement by parents, respect by friends, family, and ECE teachers. When this is done CWD are likely to develop the desires to participate in an inclusive ECE learning environment.

Additionally Solomon, Greenberg, and Pysczynski, (2009) argues that self-esteem is a major component of well-being that has been linked to overall life satisfaction while low selfesteem can lessen a learners desire to learn, his ability to focus, and his willingness to take risks, Trautwein, et al., (2006). To realize optimal participation CWD should be helped to deal with adversity. This should be through displaying CWDs' work, commenting positively on their success and praising them for hard work. This is likely to make CWD feel comfortable in the learning environment hence high participation. Learning that links to CWDs' everyday needs gives opportunities for them to work together and provide motivations for participation. Further Studies by Solomon Greenberg and Pysczynski,( 2009) on self-esteem revealed that as the level of self-esteem increases, so do achievement scores. Conversely, as self-esteem decreases, achievement scores decline. Based on this realization teachers need to focus on positive comments, provide simple responsibilities to CWD and find things that CWD enjoy doing. High-esteem is likely to promote goals, expectations, coping mechanisms and behaviors that facilitate productive achievement and impede mental and physical health problems such as school dropouts and anti-social behavior.

Self-esteem enhancement programmes should be introduced to schools for academic performance. The focus should be on enhancing self-esteem by assisting CWD to accept responsibility, communicate positive feelings, and exhibit tolerance. Without opportunities for success CWD may express their frustration through negative behavior which lessens effective participation. Self-esteem of an individual becomes wholesome when it is high. Individuals start to look outside of themselves and appreciate the contribution of others to their well-being. Similarly, Rafaeli and Steinberg (2002) affirms that individuals with high selfesteem strive to contribute to the community they are part of and feels it necessary to give something back. The individuals realize that they could not have achieved success without the help of others.

For CWD to participate successfully, they need help from parents, teachers, and peers, to assist them appreciate their own improvements by pointing to concrete signs of growth for instance, by comparing individual grades of learners at the beginning of the year and in later performances. By so doing CWD will be motivated to exhibit high levels of participation at the same time be able to communicate their feelings and emotions in a variety of situations. Individuals who are able to satisfy their esteem needs by achieving good self-esteem tend to feel confident in their abilities Maslow, (1998). However those who lack self-esteem and the respect of others develop feelings of inferiority which are barriers to participation.

Studies by Benard and Walton (2011) hold the view that self-acceptance is an element of the therapeutic process and an ingredient of well being as well as a key ingredient of contentment and individual freedom from negative emotions. In the absence of contentment individuals tend to revert to suppression and avoidance Singh (2011). Thus high levels of contentment are related to positive emotions of satisfying social relationships, achievement and adjustment to negative life events. To attain high participation there is need for CWD to be supported to develop the perception that they are worth and valuable. They need to be involved in activities such as music, painting, poetry and dance, which will enhance their participation.

Further studies by Burke (2010) indicate that self- 
acceptance involves a stance of non judgmental self awareness and actively embracing the experience of thought and positive feelings of pleasure. To support high participation for CWD their self awareness should be enhanced. This can be achieved through recognizing their talents, accepting their limitations, giving them leadership roles, making decisions and acting upon them respectively. If their self-acceptance is positive, it is likely to result in high levels of participation.

Additionally opinions of friends, peers, teachers, and family feedback play a crucial role in fostering selfacceptance. Parents have a role to play in ensuring that their disabled children participate in school and in the larger community. Studies by Council of Europe, (2012), revealed that parents' participation in provision of social needs to their disabled children resulted in promotion of positive attitudes for CWD in regard to their participation.

Acknowledging and recognizing CWDs' achievement, skills and abilities gives them a sense of confidence. A person in rational terms will experience feelings of happiness and satisfaction with his own goals when desires are met and feelings of dissatisfaction when they are not met Durante et $a l$. , (2014). In the same position the participation of CWD is expected to be high when their desires are met and low when desires are not met. For CWD, lack of self-acceptance is likely to lead to experiencing unhealthy negative feelings that interfere with their levels of participation. There is need to boost CWD's confidence by creating awareness on their strengths and weakness through giving them a chance to contribute in discussion, celebrating their improvements as well as achievement and talking about successful people living with disability. This positive attributes will strength their participation.

Over the years there have been unsuccessful attempts in Kenya to determine the disability status through national censuses and studies by civil societies, non-governmental organizations and government. Lack of evidence-based data on the nature and extent of disabilities as well as other factors that affect persons with disabilities in Kenya has therefore posed challenges in terms of planning.

Table 1. Prevalence of disabilities in Nairobi County

\begin{tabular}{|c|c|c|c|c|c|c|c|c|c|c|}
\hline \multicolumn{11}{|l|}{ Type of disability } \\
\hline \multirow{2}{*}{ Nairobi County } & None & Hearing & Speech & Visual & Mental & Physical & Self-care & Other & Total & Total disabled \\
\hline & 94.9 & 0.3 & 0.1 & 2.7 & 0.3 & 1.1 & 0.3 & 0.2 & 100 & 5.1 \\
\hline
\end{tabular}

Source: 2007 KNSPWD Kenya National Survey for Persons with Disabilities

\section{Statement of the Problem}

Unfinished explorations, coupled with unclear policies on intervention have rendered CWD slots in society. Furthermore ECE centers are still guided by policies stereotypes that tend to normalize CWD without considering their social needs, their uniqueness and their diversities. Social needs of belongingness, self-esteem and selfacceptance are as important to success in school as on the mastery of individual's skills. Disability however makes it difficult for learners to feel better about themselves and accomplish their potential to success in the future. When CWD fail to realize their potential, they may lead to later social exclusion and maladjustment difficulties. There is dire need to strengthen interventional strategies that will foster positive attributes of (problem solving, creativity, decisionmaking, responsibility, tolerance, achievement, contentment, self-awareness and confidence) if these needs are met there is likelihood of high learner participation. Hence the need for this study.

\section{Purpose and Objectives}

This study was conducted to identify social needs of CWD in pre-schools in Starehe division in Nairobi County. The study was intended to provide useful information that could facilitate improvement in providing social needs in CWD in ECE centers. The outcome of this study is particularly important for the Ministry Of Education, (MOE) policy makers, and National Center for Early Childhood Education
(NACECE) in understanding the importance of social needs. The findings will also hearten the MOE to invest more in issues concerning CWD.

\section{Theoretical Framework}

The study was founded on the theoretical framework of Maslow, (1998). He suggests that the most basic level of needs must be met for individuals to satisfy their desires. By connotation teachers, educators and parents need to start by providing CWD basic needs of food, shelter and clothing, if successful participation is to be realized. Personal needs of safety have also to be met because CWD cannot participate effectively where the environment is not safe in terms of security. It is difficult to concentrate on theoretical teaching when the environment has no security. To this step of the hierarchy, it is essential to create a safety learning environment that will enhance learner participation.

Belongingness: The CWD need to feel that they belong to a class or to a community and that they are accepted as members of the group if they are to reach the next level because interaction and belongingness helps them to feel more involved, which in turn leads to high participation.

Self-esteem: Making CWD feel that they are making a contribution and they are valued as individuals goes a long way to helping them reach the level of self-esteem. Meeting CWD social needs lays a foundation for their participation and for their future.

Acceptance: The CWD feel socially, physically and emotionally safe when adults in their lives care about them 
and supports them. For optimal learner participation to be realized CWD should be accepted as individuals with feelings, opinions, ideas, concerns, needs and wants. The CWD should also be treated in courteous, thoughtful, attentive and in a civil manner.

It is therefore expected that after providing social needs CWD will develop the skills of problem solving, creativity, decision making, confidence and achievement. These needs are key components for the participation of CWD.

\section{Conceptual Framework}

In this study the conceptual framework was used to explain the influence of social needs of (belongingness, self esteem, and self acceptance) on the participation of CWD. In cases where the social needs are not provided there is likelihood of less learner participation. Commitment to provision of sufficient social needs creates a stimulating and warm learning environment. Therefore to realize optimal learner participation, special attention should be paid to learner's social needs that accommodate all the forms of disability in ECE learning environment. The social needs should also focus on the development of positive traits such as (problem solving, creativity, decision-making, responsibility, tolerance, achievement, contentment, selfawareness and confidence). Lack of appropriate mix between social needs and disability in ECE learning centers creates a lapse in sustained participation of CWD hence less learner participation. By capturing learner's social needs, there are chances of entrenching high learner participation in an inclusive learning environment.

The experiences of CWD in an inclusive ECE environment may serve to modify negative prior expectations and is likely to succeed in transforming the participation of CWD. It is here that the teachers' attitudes and behavior pattern concerning CWD can exert some degree of influence of social needs. The possibility of reciprocal influences between social needs and participation in an inclusive ECE environment appear to be possible.

Figure 1 shows social needs and how they influence learner participation.

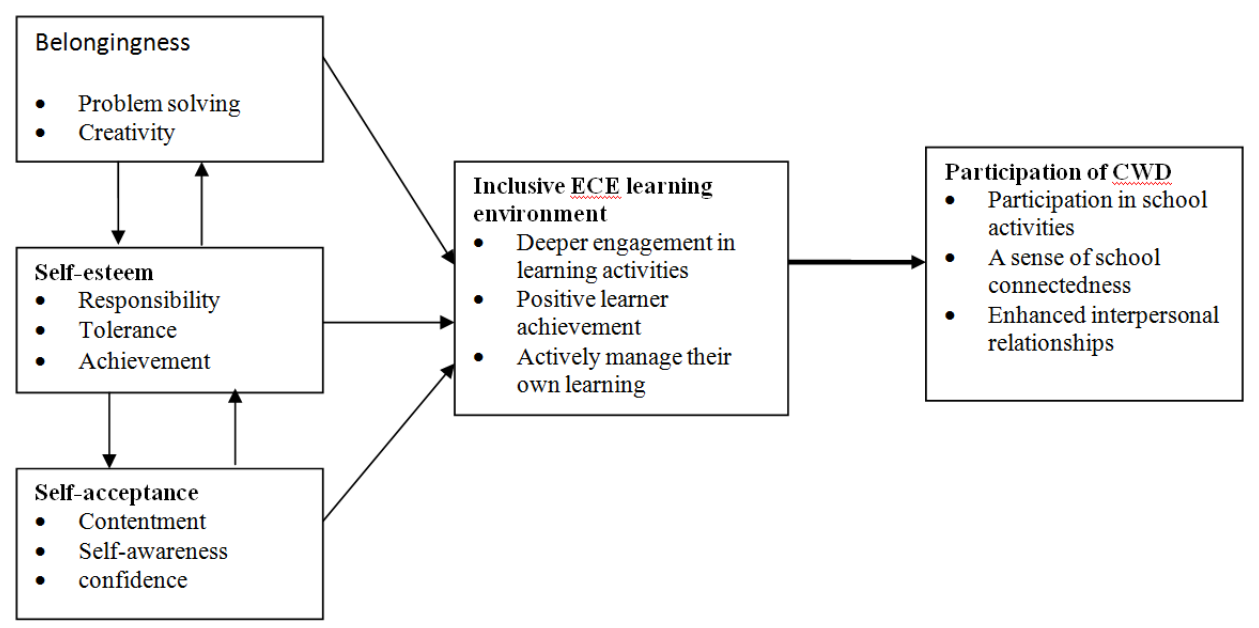

Figure 1. Conceptual framework

\section{Data and Methodology}

Research methodology is an approach and a set of supporting methods and guidelines to be used as a framework for doing research design Blessing and Chakrabarti, (2009). This study employed a descriptive research design to gather data. Descriptive studies portray an accurate profile of persons, events or situations Chandran, (2004) and describe existing conditions and attitudes through observation and interpretation techniques. The design was appropriate for this study to accurately capture data from the various intervention measures adopted by the preschools and impact of those interventions on the participation of CWD. The use of qualitative research methods in this study provided opportunity to examine and interpret patterns of instruction used by teachers.

Population is the aggregate of all that conforms to a given specification. Mugenda and Mugenda, (2003). Simple random sampling technique was used to identify five preschools. This method reduces bias in sample selection and provides the basis of making statistical inferences to the population from which the representative sample is drawn Chandran, (2004). Purposive sampling and simple random sampling were then used for this study to obtain a target population of 5 head teachers, 35 teachers, 20 parents and 20 CWD aged 4-6. According to Kerlinger, (2003), purposive sampling is characterized by the use of judgment and deliberate effort to obtain a representative sample while reducing error and increasing possibilities in analysis. Purposive sampling is useful in qualitative research design and especially in cases where data illustrates characteristics of particular subgroups of interest and also facilitates comparison, and investigator relies on expert judgment to select units that are representative or typical of the population.

The sampling frame displayed shows how respondents were distributed in the sample of this study as shown in table 1 . 
Table 2. Sampling frame of the study

\begin{tabular}{ll}
\hline Sample & No. \\
\hline Head teachers & 5 \\
Teachers & 35 \\
Parents & 20 \\
Children with disabilities & 20 \\
\hline
\end{tabular}

According to Mugenda and Mugenda, (2003), the most commonly used instruments of data collection are questionnaires, interview schedules, observations forms, standardized tests and content analysis. Instruments of data collection for this study were questionnaires, interview schedules and observation forms. The questionnaire was administered to teachers and it dealt with teachers' views on participation of CWD. An interview schedule was used to obtain information from head teachers and parents on their views concerning psychological needs of CWD. The interview schedule was used on CWD to obtain their views on their psychological needs.

Data analysis is the process of bringing order, structure and meaning to the mass of information collected. According to Jackson, (2009), descriptive research design is commonly represented by use of frequency charts, bar graphs and pie charts to tabulate the information gathered appropriately. Data collection for this study was obtained through editing, coding and tabulation procedures.

Table 3. Years of Service and academic qualifications of the Respondents

\begin{tabular}{|c|c|c|c|c|c|c|c|c|}
\hline $\begin{array}{l}\text { No. of Years of } \\
\text { Service }\end{array}$ & Frequency & $\%$ & $\begin{array}{l}\text { No. of Years of Service in } \\
\text { Current Station }\end{array}$ & Frequency & $\%$ & $\begin{array}{l}\text { Academic qualification } \\
\text { of teachers }\end{array}$ & Frequency & $\%$ \\
\hline$<1$ year & 0 & 0 & $<1$ year & 0 & 0 & P1 teachers & 8 & 22.8 \\
\hline $1-2$ years & 5 & 14.3 & 1-2 years & 3 & 8.6 & Diploma & 12 & 34.3 \\
\hline $2-5$ years & 6 & 17.1 & $2-5$ years & 10 & 28.6 & Bachelors & 13 & 37.1 \\
\hline 5 - 9 years & 10 & 28.6 & 5 - 9 years & 18 & 51.4 & Masters & 2 & 5.7 \\
\hline$>10$ years & 14 & 40.0 & $>10$ years & 4 & 11.4 & & & \\
\hline Total & 35 & 100 & Total & 35 & 100 & Total & 35 & 100 \\
\hline
\end{tabular}

\section{Study Findings}

From table 2, cumulatively $5(14.3 \%)$ out of 35 teachers had between 1-2 years of experience, $6(17.1 \%)$ had between 2-5 years of experience, $10(28.6 \%)$ had between 5-9 years of experience while $14(40 \%)$ had had over ten years of experience. This depicts that apart from $5(14.3 \%)$ who had only 1-2 years of experience. While majority of the teachers agreed to have undergone some form of training in special needs they were vocal on the need for prior experiences in handling CWD. Consequently, those who had worked for less than 5years suggested that if they had experience in handling CWD they would be better placed to assist CWD in effective participation. Thus making a link between training and experience one needs to be working with CWD over time to get hands-on experience.

Out of 35 teachers $3(8.6)$ had taught in the station from between $1-2$ years, $10(28.6 \%)$ had taught in the same station for between $2-5$ years, $18(51.4 \%)$ had taught for 5-9 years in the same station while $4(11.4 \%)$ had taught for over ten years in the same station. This indicates that the majority 18(51.4) of who had taught in the same station had experience handling CWD.

Consequently, $8(28.8 \%)$ out of the 35 teachers had P1 certificates, 12(34.3\%) had diploma, 13(37.1\%) had Bachelors degree while $2(5.7 \%)$ had Masters in Early childhood education. This indicates that the majority of teachers need to be well trained to handle CWD.

The study sought to investigate the prevalence of disabilities in Starehe division.

Table 4. Prevalence of disabilities in starehe division

\begin{tabular}{|c|c|c|c|c|}
\hline DISABILITY & AGE & GENDER & FREQUENCY & PERCENTAGE \\
\hline \multirow[t]{3}{*}{ Hearing } & 4 & Male & 1 & $10 \%$ \\
\hline & 5 & Female & 1 & \\
\hline & & Total & 2 & \\
\hline \multirow[t]{3}{*}{ Speech } & 6 & Male & 1 & $10 \%$ \\
\hline & 4 & Female & 1 & \\
\hline & & Total & 2 & \\
\hline \multirow[t]{3}{*}{ Visual } & 5 & Male & 2 & $25 \%$ \\
\hline & 4 & Female & 3 & \\
\hline & & Total & 5 & \\
\hline \multirow[t]{3}{*}{ Mental } & 4 & Male & 1 & $5 \%$ \\
\hline & 6 & Female & 0 & \\
\hline & & Total & 1 & \\
\hline \multirow[t]{3}{*}{ Physical } & 4 & Male & 6 & $50 \%$ \\
\hline & 5 & Female & 4 & \\
\hline & & Total & 10 & \\
\hline Total & & & 20 & $100 \%$ \\
\hline
\end{tabular}


From table 3 , cumulatively $2(10 \%)$ out of the 20 CWD aged 4-5 had hearing disability, 2(10\%) aged 4-6 had speech disability, 5(25\%) aged 4-5 had visual disability, 1(5\%) aged 4-6 had mental disability while the majority $10(50 \%)$ aged 45 had physical disability. These findings imply that, the most common form of disability is physical. If CWD are assisted in school through provision of social needs then high learner participation will be realized.

The study sought to examine teachers' understanding of social needs and participation of CWD.

Table 5. Teachers understanding of social needs of children living with disabilities

\begin{tabular}{|c|c|c|c|c|}
\hline \multirow{3}{*}{ Need } & \multicolumn{4}{|c|}{ Views } \\
\hline & \multicolumn{2}{|l|}{ Yes } & \multicolumn{2}{|l|}{ No } \\
\hline & No. & $\%$ & No. & $\%$ \\
\hline \multicolumn{5}{|l|}{ Belongingness } \\
\hline Do you involve CWD in problem solving activities? & 20 & 57.14 & 15 & 42.86 \\
\hline Are CWD creative? & 25 & 71.43 & 10 & 28.57 \\
\hline Do you allow CWD to participate in decision making activities? & 19 & 54.19 & 16 & 46.71 \\
\hline \multicolumn{5}{|l|}{ Self-esteem } \\
\hline Are $\mathrm{CWD}$ responsible? & 10 & 28.57 & 25 & 71.43 \\
\hline Are CWD tolerant? & 22 & 62.86 & 13 & 57.14 \\
\hline Do you give CWD challenging tasks? & 24 & 68.57 & 12 & 31.43 \\
\hline \multicolumn{5}{|l|}{ Acceptance } \\
\hline Are CWD contented? & 22 & 62.86 & 13 & 37.14 \\
\hline Do you create self awareness in CWD? & 19 & 54.28 & 16 & 45.71 \\
\hline Do you build confidence in CWD? & 18 & 51.43 & 17 & 48.57 \\
\hline
\end{tabular}

From table 4 , the study found that $20(57.14 \%)$ out of the 35 teachers reported having involved CWD in problem solving activities while $15(42.86 \%)$ did not. From these findings, one would argue that majority of teachers were conversant with the need for belongingness to CWD. These findings corroborates with the findings of(Kenrich, (2006) who found out that the child for full harmonious development of his personality needs a sense of belonging, love and understanding from the immediate environment. The data further shows that the majority $25(71.43 \%)$ of the teachers reported that CWD were creative while 10(28.57\%) reported CWD were not creative. These findings depict that CWD who feel part of the classroom community will be better to focus on building healthy relationships of belongingness. Cumulatively $19(54.19 \%)$ of the teachers allowed CWD to participate in decision making while $16(45.71 \%)$ did not. These findings indicate that most of the teachers supported CWD participation.

With regard to responsibility, $10(28.57 \%)$ reported that children with disabilities were responsible. On the other hand $25(71.43 \%)$ reported that CWD were not responsible, an indication that teachers did not develop responsibility amongst CWD. More still 22(62.86\%) reported that CWD were tolerant while $13(31.14 \%)$ reported that CWD were not. These findings corroborates with the findings of (Trzesniewki, 2005) who found out that high esteem promotes goals, expectations, coping mechanisms and behaviors that facilitates achievements. While $24(68.57 \%)$ of the teachers agreed on having given challenging tasks to CWD, 12(31.43\%) did not. This indicates that majority of the teachers supported self-esteem for CWD. These findings support the findings of Rafaeli (2002) who argued that selfesteem enhancement programs should be introduced to schools for academic performance.

Consistent with the majority opinion, 22(62.86\%) teachers reported that CWD were contended while 13(37.14\%) reported that CWD they were not. High levels of contentment are related to positive emotions of satisfying social relationships, achievement and adjustment to negative life events. Additionally, 19(54.28\%) reported that CWD had self awareness while $16(45.71 \%)$ reported that CWD had no self awareness. This suggests that majority of the teachers did not develop skills for self-awareness for CWD, an indication of less learner participation. While 18(51.43\%) reported that they build confidence in CWD, 17(48.57\%) did not. Yet, recognizing this CWDs' talents, accepting their limitations giving them leadership roles builds confidence a key ingredient for high participation. When asked about developing self acceptance to CWD one teacher said:

..........I do not have a problem handling CWD in my classroom so long as the other children are not distracted that they cannot learn. My only fear is that these disabled children will lower the grades of my class. This account portrays that the teacher was only interested in achieving high goals from CWD and had less interest in providing their social needs as suggested by UNICEF, (2003) that increasing support for CWD and shifting the emphasis towards ability requires changing attitudes and strengthening social needs at every level of the school system.

The study sought to find out parents' understanding of social needs and participation of CWD as well as CWD understanding their needs. 
Table 6. Parents' understanding of social needs and participation of CWD

\begin{tabular}{|c|c|c|c|c|}
\hline & YES & & NO & \\
\hline ITEM & No. & $\%$ & No. & $\%$ \\
\hline Do you develop problem solving skills in your disabled child? & 16 & 80 & 4 & 20 \\
\hline Is your disabled child creative? & 12 & 60 & 8 & 40 \\
\hline Is your disabled child able to make sound decisions? & 6 & 30 & 14 & 70 \\
\hline Do you train your disabled child on responsibility activities? & 14 & 70 & 6 & 30 \\
\hline Is your disabled child tolerant? & 11 & 55 & 9 & 45 \\
\hline Do you train your disabled child on achievement activities? & 8 & 60 & 12 & 40 \\
\hline Is your disabled child contented? & 10 & 50 & 10 & 50 \\
\hline Is your disabled child confident? & 8 & 40 & 12 & 60 \\
\hline Do you create self awareness activities in your disable child? & 10 & 50 & 10 & 50 \\
\hline \multirow{2}{*}{ The CWD's view } & Yes & & No & \\
\hline & No & $\%$ & No. & $\%$ \\
\hline Do you influence your friends' opinions? & 16 & 80 & 4 & 20 \\
\hline Do you like making your own decisions? & 15 & 75 & 5 & 25 \\
\hline Do you like sharing ideas? & 10 & 50 & 10 & 50 \\
\hline Do accept responsibility? & 14 & 70 & 6 & 30 \\
\hline Do you accept compliments & 13 & 65 & 7 & 35 \\
\hline
\end{tabular}

The study found that $16(80 \%)$ out of the 20 parents developed problem solving skills in their disabled children while $4(20 \%)$ did not. The findings also indicate that $12(20 \%)$ had disabled children who were creative while $8(40 \%)$ were not. Thus, unless parents take initiative in developing the skills that foster belongingness then CWDs participation will be inadequate. These findings concur with studies by Baumeister (2009) that, humans have an inherent desire to belong and to be part of something greater than themselves. When asked to comment on belongingness one parent said: .........I'm not human, am only the mother of a "handicapped" son and I don't have a mind of my own. People think am also "handicapped". They tend to forget that am a normal person like them and I lead a normal life. My self-esteem, expectations and dreams have been threatened by the presence of my disabled son. This observation indicates that there still exist barriers for participation such as cultural attitudes, values, myths about disability and low expectations (Davis and Watson, 2001).

Further findings showed that $6(30 \%)$ had children able to make sound decisions while $14(70 \%)$ did not, consequently $14(70 \%)$ trained their disabled children in responsibility while $6(30 \%)$ did not. Furthermore $11(55 \%)$ of their disabled children exhibited tolerance while $9(45 \%)$ did not. Similarly, $8(60 \%)$ trained their disabled children on achievement activities while $12(40 \%)$ did not. This implies that there is laxity on the part of parents' roles in providing social needs efficiently. A close look at the findings indicates that $10(50 \%)$ had disabled children who were contented while 10(50) were not, $8(40 \%)$ had disabled children who were responsible while $12(60 \%)$ were not. Additionally $10(50 \%)$ developed awareness skills in their children while $10(50 \%)$ did not. This finding implies that unless parents take initiative in providing social needs, CWD will not participate.

Further findings showed that $16(80 \%)$ out of 20 respondents had influence on their friends opinions while $4(20 \%)$ did not. Additionally, 15(75\%) made their own decisions while 5(25\%) did not. Consequently, 10(50\%) shared ideas while $10(50 \%)$ did not. Furthermore $14(70 \%)$ accepted responsibility, 6(30\%) did not, while 13(65\%) accepted compliments. However 7(35\%) did not accept responsibility. The findings indicate that most of the CWD have developed positive perceptions that are worth and valuable. These findings depicts the argument of Singh (2011) that high levels of contentment are related to positive emotions of satisfying social relationships, achievements and adjustment to negative life events. However, one disabled child lamented:

.........I feel bad when I am isolated by my friends because I look different from them. Most of them do not allow me to play with them because am not as fast as them. This observation replicates the findings of McMahon et.al, (2008) who found out that when children belong to a social group and when they are accepted and welcomed, they develop positive emotions such as happiness, elation, calmness and satisfaction.

The study sought to investigate the views of head teachers on participation of CWD. 
Table 7. Views of Head teachers on participation by CWD

\begin{tabular}{|c|c|c|c|c|}
\hline \multirow[b]{2}{*}{ Item } & \multicolumn{2}{|c|}{ Strongly agree } & \multicolumn{2}{|c|}{ Agree } \\
\hline & NO. & $\%$ & No. & $\%$ \\
\hline CWD needs love and assurance. & 4 & 80 & 1 & 20 \\
\hline CWD needs to build positive relationships. & 4 & 80 & 1 & 20 \\
\hline CWD acquire positive attention. & 3 & 60 & 2 & 40 \\
\hline CWD needs positive compliments. & 5 & 100 & 0 & 0 \\
\hline Find areas of strength and weakness in CWD & 3 & 60 & 2 & 20 \\
\hline Promote equal participation for CWD. & 5 & 100 & 0 & 0 \\
\hline Foster teamwork for CWD. & 5 & 100 & 0 & 0 \\
\hline Use core values in making decisions for CWD. & 3 & 60 & 2 & 40 \\
\hline Clarity choices in CWD. & 4 & 80 & 1 & 20 \\
\hline
\end{tabular}

The findings from table 6 depicts that $4(80 \%)$ out of 5 head teachers strongly agree that CWD need love and assurance from the immediate environment, 1(20\%) agree. Additionally $4(80 \%)$ strongly agree that CWD need positive relationship while 2(20\%) agree, Furthermore 3(60\%) strongly agree that CWD need positive compliments while $2(40 \%)$ agree. This indicates that majority of head teachers understand the importance of providing social needs to CWD. Additionally, the findings corroborates with the findings of (Kenrich, 2006) who asserts that the child, for harmonious development of his personality needs love and understanding from the immediate environment. In one instance a head teacher said:

............Being disabled should not hinder CWD from any activities. I feel motivated and encouraged when I see CWD compete fairly with children without disabilities. This observation agrees with the findings of Solomon, Greenberg and Pysczynski,( 2009) that high self- esteem promotes goals expectations, coping mechanisms and behaviors that facilitate productive achievement

Further findings show that $5(100 \%)$ strongly agree that CWD's strength and weaknesses should be focused on while $3(60 \%)$ strongly agree on the need to promote equal opportunities while $2(40 \%)$ only agree. Consequently, 3(60\%) strongly agree on the use of core values in making decisions for CWD while $3(60 \%)$ strongly agree on clarifying choices for CWD. This indicates that majority of head teachers understand that participation for CWD depends on provision of social needs.

\section{Recommendations}

Based on the conclusions, the researcher made the following recommendations:

1. The Government and the Ministry of Education should promote awareness and the importance of social needs to CWD.

2. Provision of social needs of belongingness, self esteem and self acceptance should be strengthened in ECE learning environment.

3. The Ministry of Education should ensure that ECE learning environment tailor their facilities to suit social needs of CWD.

4. Mechanisms should be put in place to mitigate barriers to participation of CWD.
5. There is need for strong legislation, policy and practice across ECE school system.

\section{References}

[1] Aldao, A. Nolen Hoeksema,,S. Schweizer S. (2010).Emotionregulation strategies across psychopathology: a meta-analytic review. Clinical Psychology Review, 30, $217 \mathrm{e} 237$.

[2] Baumeister ,R..F. Masicampo, E.J. DeWall C.N. (2009) .Prosocial benefits of feeling free: Disbelief in free will increases aggression and reduces helpfulness. Personality and Social Psychology Bulletin, 35, 260-268.

[3] Bernard, ME. Walton, K. (2011).The effect of you can do it! Education in six schools on student perceptions of well being, teaching-learning and relationships. Journal of student wellbeing.

[4] Blessing, TM. Lucienne, Ameresh Chakrabart, DRM (2009). A Design Research Methodology" Springer Verlay, London, U.K.

[5] Burke, C. A. (2010). Mindfulness-Based approaches with children and adolescents: A preliminary review of current research in an emergent field. Journal of Child and Family Studies, 19(2), 133-144.

[6] Carter, M. Curtis, M. Curtis D. (2003). Designs for living and learning. Transforming early childhood environments. St Paul, Minnesota: Rodleaf Press.

[7] Chandran, VGR. Veera ,P. (2004).Research Methodology: A simple Guide for Business Undergraduates, University Publication Centre, UITM press.

[8] Council of Europe. (2012). Revised European social charter: 5 th national report on the implementation of the revised European social charter submitted by the government of the Netherlands. Strasbourg.

[9] Davis, JM. Watson, M. (2001) .Where are the children's experiences? Analyzing social and cultural exclusion in "special" and "mainstream" schools. Disability and society, 16(5): 671-687.

[10] DeWall, CN. Pond, RS. Deckman, T. Bonser, I. (2011).Belongingness as a core personality trait: How social exclusion influences social functioning, and how the need to belong influences personality expression. Journal of Personality, 79, 1281-1314.

[11] Durante, Kristina, M., Vladas Griskevicius, Stephanie M. Cantu,and Jeffry A. Simpson (2014). "Money, Status, and the Ovu-latory Cycle,'Journal of Marketing Research,51(1),27-39 
[12] Galambos, NL. Barker, ET. Krahn, HJ. (2006)Depression, Self-esteem, and Anger in Emerging Adulthood:Seven-Year Trajectories.Developmental Psychology.42:350-365.

[13] Jackson, SL. (2009).Research Methods and Statistics: A Critical Thinking Approach $3^{\text {rd }}$ edition. Belmont, CA: Wadsworth.

[14] Jones, E. C. and A. D. Murphy .2008. Review of CrossCultural Disaster Studies Concerning Latin American Populations. In Libro Homenaje a Fernando Pozos. F. Leal Carretero, ed. Guadalajara: University of Guadalajara Press

[15] Kenrich, DT. (2006).A Dynamical Evolutionary View of love in R.J. Sternberg and K. (Eds) the New Psychology of love. New Havin: Yale University Press.

[16] Kerlinger, P. (2003).Addendum to the Phase Iavian risk assessment for the Flat Rock Wind Power Project, Lewis County, New York: Phase One and Phase Two. March 31, 2003. Report to Flat Rock WindPower, L.L.C.

[17] Macy, M., \& Bricker, D. (2007). Embedding individualized social goals into routine activities in inclusive early childhood classrooms. Early Child Development and Care, 177(2), 107120

[18] Maslow, A. Lowery, R. (ED) (1998). Towards a psychology of being ( $3^{\text {rd }}$ Ed.) New York: Wiley \& Sons

[19] McMahon, SD. Parnes, AK. Keys, CB. Viola, JJ. (2008).School belonging among low-income urban youth with disabilities: Testing a theoretical model. Psychology in the schools 45(5): 387-401.

[20] Mugenda, MO. Mugenda, GA. (2003).Research methods: Quantitative and Qualitative approaches. Laba graphics services.

[21] Oriedo, T. (2003).The state of persons with disabilities in Kenya. Council for Exceptional Children: Division of International Special Education and Services. Retrieved July 18. 2003, from http://www .cec.sped.org/intl/natlover.html
[22] Osundwa, E. (2007). "The Employment of Visually Impaired People in Kenya." Paper presented at the WBU Fourth Africa Forum on Jamii Jumuishi - Social Inclusion, 6-11 May, 2007, Nairobi, Kenya

[23] Rafaeli-M, E. Steinberg, J. (2002).Self-complexity and wellbeing: A review and research synthesis. Personality and Social Psychology Review, 6, 31-58.

[24] Rauch, D. (2011).Conscious Capitalism: A better Road Map: A response to James O'Toole and David Vogel's "Two and Half Cheers for Conscious Capitalism." California Management Review, 53 (3), pp. 91-97.

[25] Richard, Burkhauser, Mary, Daly (2002)."United States Disability Po,licy in a Changing Environment". Journal of Economic Perspective 16 (1).

[26] Singh, S. Tanu (2011) Personal Influences in Depression among Female Adolescents. Journal of the Indian Academy of Applied Psychology 37: 40-46

[27] Solomon, S. Greenberg, J. and Pysczynski, T. (2009). Pride and prejudice: fear of death and social behavior. Current Directions in Psychological Science, 9, 200-204.1.

[28] Trautwein, U. Lüdtke, O. Köller, O, Baumert, J. (2006).Selfesteem, academic self- concept, and achievement: How the learning environment moderates the dynamics of self- concept. Journal of Personality and Social Psychology 90: 334-349. CrossRef.

[29] UNESCO. (2005).Guidelines for inclusion: Ensuring access to Education for all.

[30] UNICEF. (2003).Inclusive Education Initiatives for Children with Disabilities: Lesson from East Asia and Pacific Region.

[31] World Bank. (2007): Social Analysis and Disability: A Guidance Note.39385Washington, DC: Social Development Department, World Bank. 